\title{
A Investigação de Acidentes Industriais: uma entrevista com Michel Llory
}

\section{The Investigation of Industrial Accidents: an interview with}

\section{Michel Llory}



Email: floravezzaœusp.br

\section{Resumo}

Michel Llory, engenheiro especialista em segurança e acidentes industriais, concedeu uma entrevista à Saúde e Sociedade na qual apresenta um pouco de seu percurso pessoal e profissional e discute que caminhos deveriam ser trilhados por aqueles que se interessam pela análise e prevenção de acidentes industriais e do trabalho. Michel Llory desenvolveu o Serviço de Análise de Riscos da Electricité de France, empresa responsável pela geração de energia elétrica na França. Este serviço foi responsável pelas pesquisas aplicadas relacionadas à segurança do parque francês de usinas nucleares. Michel Llory escreveu várias obras sobre a análise de acidentes, sua paixão, e também romances. Nesta entrevista, ele destaca questões sobre os métodos de investigação e as relações entre o gerenciamento das empresas e o risco de incidentes e acidentes; ele aponta também a importância de uma abordagem dos acidentes que seja descritiva, pessoal, engajada, que resgate historicamente a evolução das condições internas das empresas e seu contexto.

Palavras-chave: Análise de acidentes industriais e de trabalho; Prevenção de acidentes industriais; Abordagem sóciotécnica. 


\section{Abstract}

Michel Llory, engineer specialized in industrial safety and accidents, conceded an interview to Revista Saúde e Sociedade where he shares aspects of his personal and professional trajectory and discusses what paths should be taken by those who want to analyze and prevent industrial and occupational accidents. Michel Llory created the Risk Analysis Department at Electricité de France, enterprise responsible for the generation of electric energy in that country. This service was responsible for the applied researchs related to safety of French nuclear plants. Michel Llory wrote a large number of works about accident analysis, his passion, and some romances too. In this interview, he points out some questions about the investigation methodologies and the relationship between the enterprises' management and the risk of accidents and incidents; he also highlights the importance of a descriptive approach, of a personal, engaged narrative that retrieves the historical evolution of the enterprises' conditions and their context.

Keywords: Analysis of Occupational and Industrial Accidents; Industrial Accident Prevention; Sociotechnical Approach.
Em junho de 2012, o Fórum Acidentes do Trabalho: Análise, Prevenção e Aspectos Associados ${ }^{1}$ promoveu seu $30^{\circ}$ Encontro Presencial, convidando o Engenheiro Michel Llory ${ }^{2}$, especialista em segurança e acidentes industriais, para uma série de quatro Conferências no Brasil, sendo três realizadas em São Paulo (duas na Capital, uma em Piracicaba) e a última no Rio de Janeiro. Além das Conferências, Michel Llory concedeu uma entrevista à Saúde e Sociedade.

Saúde e Sociedade: Professor, iniciando nossa conversa, gostaríamos que o Senhor nos fizesse um breve relato de sua trajetória profissional, começando com uma formação em engenharia, em geral bastante objetivista, positivista até, e a situação atual, em que sua produção é fortemente influenciada pela contribuição das ciências humanas, quase se tornando um poeta.

Michel Llory: Bem, eu apresentarei aspectos muito pessoais. Para começar, devo dizer que eu muitas vezes me senti alguém dividido, paradoxal, eventualmente contraditório. Outro aspecto importante é que eu tenho raízes no campo, muito profundas, que não se percebe, mas que são muito profundas, e isso tem um papel importante na minha visão das coisas. Na verdade, eu não queria ser engenheiro, eu queria ser médico, mas circunstâncias familiares particulares me levaram a seguir a carreira de engenheiro. Bem, estes estudos de engenharia me permitiram desenvolver certo rigor e também um gosto que eu tinha pela matemática, que é completamente paradoxal, pois eu não tinha necessidade dela, visto que queria ser médico; mas eu tinha uma fascinação pela matemática. Olhando para trás, eu penso que eu tinha uma personalidade bem difícil, muitas vezes durante o curso de engenharia eu me refugiava... Porque eu achava que meus colegas eram pouco cultos, não valorizavam a literatura, a filosofia, achavam que elas não serviam absolutamente para nada em termos de carreira. Eu me refugiava na

\footnotetext{
1 Informações mais completas sobre as Conferências com Michel Llory podem ser obtidas na página e no canal YouTube do Fórum, acesso pelo endereço: http://www.moodle.fmb.unesp.br/course/view.php?id=52

2 M. Llory mantém um site e um blog onde podem ser encontradas mais informações sobre sua obra e sua trajetória: http://www.michel-llory. com/ (em francês).
} 
leitura da filosofia, na literatura, como um suporte para este conflito. Eu me lembro de uma historia, eu saí de uma aula prática de quatro horas com um colega de curso. Eu tinha um livro que aparecia no bolso; meu colega puxou e percebeu que era um livro de poesia, e me perguntou: "O que é isso, poesia? Isso aqui não serve para nada!”

Eu comecei a trabalhar, e ao mesmo tempo eu tinha consciência de algumas dificuldades de relacionamento, em particular com as mulheres, e resolvi fazer psicanálise. Eu continuei a desenvolver minha atividade profissional, e em paralelo eu tive uma experiência aprofundada de análise psicanalítica durante cinco anos, várias vezes por semana, e isso certamente me transformou muito. E não é por acaso que eu fiz muitos amigos - e a gente fez um percurso de vida juntos - no mundo dos psicanalistas.

Com relação ao meu percurso profissional, ele é de certa forma pouco convencional. Ele se iniciou na Electricité de France (EDF), uma empresa pública de produção de energia elétrica que gerencia um parque nuclear muito grande, onde trabalhei durante 17 anos. Em 1977, eu fui designado para trabalhar sobre os riscos de acidentes. De fato, num primeiro momento eu me dediquei a estudos probabilísticos sobre o risco de problemas nas centrais nucleares. Coincidentemente, dois anos depois de meu início neste setor, ocorreu o acidente nuclear de Three Mile Island, nos Estados Unidos. Isso foi um acontecimento muito importante, não só para a EDF mas para outras empresas, pois foi o primeiro acidente deste tipo. Até este momento, as concepções sobre estes assuntos eram oriundas da engenharia, mas rapidamente foi preciso descobrir conceitos relacionados à abordagem dos fatores humanos e do erro humano. Rapidamente este problema atingiu proporções muito grandes. Por causa deste acontecimento, a EDF me encarregou de criar um departamento que reunisse especialistas sobre o fator humano - ergonomistas, psicólogos do trabalho, sociólogos do trabalho - que trabalhariam juntamente com a equipe de engenharia da empresa para criar conhecimentos sobre a questão dos fatores humanos. Os anos se passaram; este departamento foi palco de muitas situações de conflito, porque os engenheiros da EDF tinham muitas vezes dificuldades de compreender a forma de abordagem do trabalho que era feita pelos especialistas do departamento. Eles tinham formas de abordagem dos problemas muito distintas, mas, apesar disso, gozavam de grande liberdade na EDF.

Porém, pouco a pouco a evolução do cenário fez com que a consideração dos riscos evoluísse para uma concepção de segurança muito mais rígida, e isso fez com que o debate fosse diminuindo no seio da empresa. Face a esta mudança, e graças à minha curiosidade pessoal com relação aos acidentes, no fim dos anos 1980 eu parti para um caminho individual de pesquisas sobre o risco. Nesta época eu trabalhava com frequência com pesquisadores de universidades francesas, dos quais alguns talvez sejam conhecidos de vocês - Maurice de Montmollin, Alain Wisner, François Daniellou, Christophe Déjours... Apesar disso, eu sentia que mesmo na universidade havia muito pouco interesse sobre o acidente. Foi devido a este interesse pessoal no assunto que em 1993 eu resolvi sair da EDF e criar uma consultoria independente sobre os acidentes industriais.

Desde então, meu interesse pelo estudo dos acidentes persiste, e corre em paralelo a minha atividade profissional. Criamos um grupo que reúne profissionais de várias formações (engenheiros, ergonomistas, sociólogos, psicólogos); há nele um núcleo estável de profissionais, e uma parte flutuante de profissionais que se juntam ao grupo, permanecem um período e partem para outros caminhos, mas o grupo persiste e está focado no estudo dos acidentes. Por causa deste interesse, fui levado a escrever várias obras sobre o assunto: um primeiro livro traduzido para o português - "O custo do silêncio" ${ }^{3}$, e posteriormente outras obras incluindo um livro sobre o Acidente da Three Mile Island ${ }^{4}$.

Além do meu interesse pelos acidentes, sempre houve de minha parte uma preocupação com a importância da escrita e um desejo de escrita - eu sou também escritor de romances. Para mim, esta preocupação com a escrita é uma questão metodologicamente importante. No fim de 2010, foi publicado um pequeno livro, fruto do trabalho deste grupo de

\footnotetext{
3 M. Llory. "Acidentes industriais - o custo do silêncio", MultiMais Editorial, Rio de Janeiro, 1999.(Edição Esgotada). 4 M. LLORY, L'accident de la centrale nucléaire de Three Mile Island, Editions L’Harmattan, Paris, 1999.
} 
debates, que muitas vezes são muito vivos e bem movimentados. Este debate aprofundado resultou na redação por mim e um colega engenheiro deste livro, que se chama "O acidente e a organização" Em paralelo, eu escrevi também um livro chamado "Une enquete explosive", publicado no fim de 2010, que é de certa forma autobiográfico e reúne em estilo romanceado minha experiência na investigação de acidentes industriais. O livro mostra que há um campo aberto para discutir a questão das investigações de situações de risco, e recebeu uma menção honrosa em um prêmio literário, que muito me honra.

Saúde Sociedade: O Brasil está intensificando a exploração e o refino do Petróleo especialmente com a prospecção em camadas profundas, o Pré Sal. Como você vê os riscos na exploração e refino de Petróleo?

Michel Llory: Há muitos dados de toda ordem sobre os problemas de exploração de petróleo no Mar do Norte. Há muitas plataformas, houve acidentes, como os incêndios e explosões que ocorreram na plataforma Piper Alpha. Houve vazamentos que produziram pequenas marés negras, e soube-se recentemente que mesmo as companhias norueguesas, por exemplo, que são reputadas como tendo um altíssimo nível de segurança, apresentaram um afrouxamento das normas de segurança e tiveram "quase-acidentes".

Assim, mais uma vez, frente a um perigo eventual de exploração intensiva com riscos importantes, eu penso que nós, profissionais ligados à segurança, temos que trazer a público a história destes problemas, quer dizer, recolocar a situação em termos de história: em todas as situações sempre houve acontecimentos anteriores, incidentes, acidentes, conflitos, processos que se passam nas empresas, que podem ser recenseados, e eu acho que é extremamente importante fazer este trabalho de preservação da memória, pois há uma tendência de esquecer o que ocorreu anteriormente.

O segundo objetivo ao qual devemos atender é o de promover, desenvolver esta ideia fundamental de que os riscos não estão ligados essencialmente aos operadores que estão na empresa, e sim a decisões tomadas em níveis hierárquicos muito altos. De uma parte, fazer com que se tome consciência de que processos de decisão muito distantes e anteriores à operação direta é que têm um papel decisivo, e que os modos de gestão, de administração (que não necessariamente são conhecidos pelos operadores), tudo isso tem uma influência considerável no momento do acidente. É preciso deixar claro que os riscos não estão ligados às ações individuais dos operadores: são as formas de administração, são decisões administrativas e gerenciais tomadas muito a montante do local das operações que agem como determinantes na produção dos riscos.

Por exemplo, seria útil lembrar o acidente de "Deepwater Horizon", que é recente e foi bem documentado, e que provocou uma maré negra no Golfo do México. 0 diretor da British Petroleum (BP) foi seriamente questionado, foi demitido, saiu da empresa, o que prova bem que em um certo número de situações graves se reconhece a responsabilidade destes níveis hierárquicos na produção de acidentes.

Após o acidente da Columbia, o administrador, Dan Golding, foi demitido, e a própria diretora da missão, Linda Ham, que teve um papel muito desfavorável na ocorrência do acidente da Columbia, foi totalmente excluída da gerência deste tipo de missão.

Para concluir, eu penso que tudo que pudermos fazer para mostrar as relações, as articulações entre certos modos de administração, as pressões de produção, etc., e, por exemplo, o aumento do número de acidentes do trabalho, dos acidentes, dos quase acidentes, ou dos incidentes, todo este trabalho sobre outros exemplos, de indústrias vizinhas, é o trabalho que nos cabe.

Para enriquecer este trabalho da equipe de interessados pela segurança, eu acho interessante incluir a sugestão de que sejam estudados os processos legais, pois em certo número de casos - na Europa, pelo menos - as gerências, os responsáveis foram responsabilizados. É preciso explicar aos gerentes que eles podem ser processados, que há riscos jurídicos.

5 M. Llory e R. Montmayeul L'accident et l'organisation. Bordeaux, Éditions Préventique, 2010. 
Recentemente, um processo contra gerentes de empresas que fabricavam produtos à base de amianto na Itália teve bastante repercussão na França, após a publicação de uma obra sobre o assunto. Dois destes dirigentes foram condenados, pela primeira vez que eu saiba, a penas de prisão fechada ${ }^{6}$.

Saúde Sociedade: Gostaríamos de saber sua opinião sobre a situação da segurança nuclear, particularmente considerando o acidente de Fukushima. $O$ que aconteceu lá foi algo que nunca tinha sido visto antes: três reatores foram afetados e provocaram vazamentos. Acidentes antes considerados impossiveis acontecem em três reatores! Enós temos hoje uma grande demora na elaboração do relatório de análise, aparentemente um processo de muita disputa, de ocultação de informação e com influências do grupo produtor de energia nuclear na condução da investigação assim como na divulgação de idéias sobre o que poderia ser feito para melhorar a segurança nuclear no mundo. Até porque numa boa parte de países, como aconteceu na Europa, a opção foi simplesmente abandonar a utilização de energia nuclear. Como o Senhor vê este processo e que lições, que cuidados os países que utilizam a energia nuclear, e nos quais a decisão de utilização termina não sendo da sociedade, precisam tomar para melhorar a segurança desses processos?

Michel Llory: Podemos falar um pouco de Fukushima. Eu vou dar minha opinião, pois, como vocês, como todo mundo, eu acompanhei as notícias sobre Fukushima durante um mês, o primeiro mês, através da imprensa, que informava de maneira bastante correta sobre o que se passava lá. Eu confesso que durante certo tempo eu fiquei estupefato, eu fiquei pasmo! Eu estava quase que incapaz de pensar qualquer coisa sobre a situação de Fukushima, enquanto que habitualmente, quando escutamos falar de um acidente, com apenas alguns dados que a boa imprensa nos dá já se pode falar "Bem, é sempre a mesma coisa, vamos cair sobre os mesmos problemas, a mesma coisa se repete: Bhopal, Three Mile Island, o acidente da Herald of Free Enterprise, vamos cair sobre os mesmos problemas..." Mas neste caso eu não conseguia pensar em absolutamente nada.

E isso é, em minha opinião, uma questão muito importante: "Somos capazes de pensar alguma coisa? O que é que se pode pensar sobre uma situação?" 0 primeiro reflexo é a rejeição total. E a este respeito, o que ocorreu na França foi que rapidamente havia uma grande oferta de obras em francês sobre o assunto, traduzidas do japonês. Eu tenho em casa uns quinze livros sobre o assunto - quinze porque a certa altura eu parei de comprar - contando aspectos sobre o horror de Fukushima, as consequências de Fukushima...

Eu consegui recomeçar a pensar sobre Fukushima quando me dei conta que, após o tsunami, só se falava do acidente nuclear de Fukushima e ninguém falava nada do risco químico! Ora, a maior parte das indústrias químicas não é protegida contra terremotos, a maior parte das indústrias tinha sido destruída, os depósitos de produtos químicos tinham sido esmagados, e ninguém falava nada do risco químico! E isso me perturbou muito. Eu fiz uma pesquisa longa na internet, mas a cada vez que eu digitava risco químico - tsunami, eu era remetido a Fukushima! Eu só achei em minha pesquisa um único artigo de um jornalista americano que colocava a questão “E o risco químico?" Então, eu propus ao editor do livro "O acidente e as organizações", que é também editor de uma revista científica, a redação de um artigo - que foi publicado - que se chama "O buraco negro do risco químico"7.

Neste artigo bem curto, eu defendo a posição de que não se trata de minimizar o risco nuclear de Fukushima, mas que é preciso dar a justa medida ao conjunto dos riscos que foram desencadeados pelo tsunami, inclusive do risco químico. E em um segundo momento esta ideia me fez lembrar de algo que eu conhecia muito bem, mas que estava escondido na memória: eu me lembrei do desastre sanitário de Minamata. Conto aqui um pouco de história: Eu e minha esposa fazíamos uma pequena

\footnotetext{
60 autor refere-se à obra de Giampiero Rossi, intitulada "Amianto. Processo alle fabbriche della morte", publicada em 2012, pela Editora Melampo. A obra "A lã da salamandra”, do mesmo autor, foi traduzida no Brasil com apoio da Associação Brasileira dos Expostos ao Amianto. (Nota da Tradução).

7 « Le trou noir des risques chimiques »: http://www.michel-llory.com/blog/article-du-blog-test-1 (Nota da Tradução).
} 
viagem a Lisboa, Portugal. Nós temos a mania de visitar a maior livraria de cada cidade que visitamos, e estávamos em Lisboa, eu fuçava na livraria quando me deparei com um pequeno livro que na época me deixou boquiaberto, de Eugene Smith, que é fotógrafo e que fotografou o desastre de Minamata. Isso me interessou muito. Uma das fotos de Eugene Smith esteve na primeira página de várias revistas americanas, da Newsweek em particular, e ajudou a tornar o desastre de Minamata, que até então era muito pouco conhecido nos Estados Unidos, conhecido do grande público americano. Para contar rapidamente a história, este desastre sanitário de Minamata fez 30.00o, 40.00o mortos, não se sabe ao certo o número de vítimas; foi devido ao envenenamento de uma baía pelos dejetos químicos de uma empresa chamada Chisso, dejetos que continham mercúrio orgânico.

É sem dúvida, juntamente com Bhopal, o mais grave desastre sanitário devido à química, e mesmo provavelmente o mais grave acidente de toda a indústria. E lembrando de Minamata, meu espírito voltou a funcionar. Eu me lembrei - vocês me dirão "isso não tem nada a ver!" - Eu me lembrei de uma frase dita pela cosmonauta Sally Ride, que foi a primeira mulher a ir para o espaço em um ônibus espacial. Ela foi a única pessoa a participar das duas comissões de inquérito - do ônibus espacial Challenger, em 1986, e o da Columbia, em 2003. Ela fez uma observação que me parece fundamental, que está no relatório da Columbia. Durante esta investigação, ela declarou: "Há ecos da Challenger na Columbia".

Esta é uma observação muito pertinente, e que pode ser generalizada, pois quando se estuda muitos acidentes percebe-se ecos de certos acidentes em outros - pontos em comum, caminhos repetidos, uma série de procedimentos semelhantes. Eu comecei a pensar e se tornou claro que havia muitos ecos de Minamata no acidente de Fukushima. 0 acidente de Minamata foi muito bem estudado, há vários estudos que foram feitos. Entre as várias obras sobre o assunto, uma em particular ficou bastante conhecida - Bitter Sea (Mar Amargo) - com o subtítulo "O custo humano da síndrome de Minamata”. A partir daí se percebe que há uma história japonesa que pode ser observada a partir da Segunda Guerra Mundial, que apresenta ecos neste desastre e que é extremamente desfavorável à segurança.

O que se verificou é que houve um conluio geral organizado entre a indústria japonesa, as autoridades de segurança governamentais, a imprensa e mesmo uma parte das universidades, voltado a criar um silêncio para esconder os problemas provocados por um desenvolvimento industrial intensivo que tinha como objetivo alcançar o mundo ocidental.

Para citar dois exemplos entre muitos possíveis, pesquisadores universitários japoneses concordaram em escrever relatórios completamente falsos para mostrar que as causas do envenenamento dos pescadores não eram devidas à indústria química. E há uma história que eu acho que se fosse contada em um romance ou filme seria considerada totalmente inverossímil! Nos anos 1970, a pressão popular era tal que o governo japonês obrigou a Chisso a instalar um sistema de tratamento dos dejetos que jogavam o mercúrio na baía. A Chisso instalou um sistema chamado Ciclator. Um dia, com grande pompa e grande cobertura midiática, o presidente diretor geral da Chisso pegou um copo da água que saía do Ciclator e bebeu a água. E todos disseram "Olhem, formidável! A água está limpa, a Chisso resolveu o problema!" E os médicos japoneses, os epidemiologistas que acompanhavam os doentes disseram "Que ótimo, a partir de hoje não haverá mais casos de envenenamento!"

Ora, nos anos seguintes continuou-se a observar novos casos de envenenamento. E descobriu-se depois que os dejetos químicos que deveriam ser tratados pelo Ciclator tinham sido direcionados para outra tubulação, e que o que passava por ele era água pura. E agora se começa a ter dados suficientes sobre Fukushima para reencontrar aproximadamente o mesmo esquema de conluio, talvez menos forte porque agora há reação de parte da imprensa, dos pesquisadores, de universitários, de escritores, etc. Mas se reencontra este fenômeno de conluio completo entre a TEPCO e a autoridade de segurança japonesa. Há por exemplo um fenômeno muito perturbador: normalmente havia o registro das discussões de equipe que conduziam à tomada

8 Bitter Sea: The human cost of Minamata disease., Escrito por Akio Mishima com prefácio de Lester R. Brown. 
de decisões importantes que tentavam conter a degradação da situação, e estes registros foram destruídos depois do tsunami, enquanto a situação ia se deteriorando nos reatores.

Ora, nós, analistas de segurança, eu acho que temos que manter a calma. Nem sempre é fácil, mas é preciso evitar estabelecer uma relação entre Hiroshima e Fukushima. Isso é o que foi feito em praticamente todos os livros que saíram na França, enquanto que, em minha opinião, a verdadeira relação que existe e que deve ser trabalhada é entre Minamata e Fukushima. Além disso, eu acho que não se deve focalizar sobre as consequências - eu acho que é importante, naturalmente, mas não se pode focalizar exclusivamente sobre as consequências, é preciso que a gente se interesse pelas causas dos desastres importantes, é isto o que nos fará crescer em termos de segurança.

Portanto, nosso primeiro dever, me parece, é instruir o inquérito. Isto quer dizer buscar na história industrial japonesa a compreensão do que poderia ter acontecido em Fukushima. Além disso, interessar-se também pela maneira pela qual o acidente foi gerenciado, pois o acidente durou, como em muitos outros casos, certo período de tempo, alguns dias, meses, e neste intervalo justamente é interessante investigar como o acidente foi administrado. As informações que eu tenho sobre as primeiras horas depois do acidente mostram que a TEPCO teria tentado ao máximo preservar o reator antes de se engajar em uma reação forte, agressiva frente ao acidente, de medidas mais drásticas de controle do acidente, em particular afogando o reator com água do mar.

Além do que, isso corresponde aos dois grandes objetivos da segurança: reduzir o mais possível a probabilidade do acidente, através do estudo de suas causas; mas como não se pode garantir que o acidente não se produzirá, limitar o número de consequências possíveis, o que os americanos chamam "mitigation". E para concluir sobre esta questão do nuclear, provisoriamente, é claro, eu penso que é preciso reconhecer que se uma empresa aceita a gestão - e isso não é uma questão pessoal, algo que se possa ajustar pessoalmente, pois é uma questão social - se se aceita (em termos de aceitabilidade do risco) o risco da gestão do nuclear, é preciso que os industriais, o estado, o governo, as autoridades de segurança aceitem também condições extremamente draconianas para garantir as condições de segurança.

É preciso aceitar controles muito frequentes, completamente independentes, muitas vezes internacionais, pois em caso de acidentes pode-se atingir os países vizinhos; é preciso aceitar a continuidade de todas as pesquisas, técnicas, é claro, mas também das ciências humanas, sociais, da ergonomia, etc. Não se pode dizer "Eu construí uma central nuclear" e colocá-la em funcionamento ... É preciso uma infraestrutura material e intelectual muito elaborada.

Saúde e Sociedade: Para encerrarmos, quais seriam suas recomendações não apenas para o pessoal que trabalha com a segurança, mas também para os técnicos de agências governamentais de controle das condições de trabalho, controle de riscos, etc?

Michel Llory: Eu posso dar conselhos que estão ligados à minha história pessoal. 0 primeiro seria o seguinte: acredito que se deve criar, se ainda não existem, ou desenvolver, favorecer a existência de fóruns de discussão, de debates interprofissionais entre profissionais de segurança, engenheiros, agentes do governo; debates abertos, informais ou pouco formais, onde se possa em suma ter aquilo que os especialistas em ciências humanas chamam de 'palavra autêntica'. Um espaço no qual os profissionais possam expressar suas preocupações em relação ao seu trabalho. Portanto é importante que estes espaços sejam abertos e se multipliquem.

O segundo ponto, em minha opinião, é que nós devemos fazer um esforço permanente de curiosidade, de investigação interdisciplinar, de procurar em muitos lugares diferentes, em todas as áreas do conhecimento. Neste sentido, acredito que é particularmente útil o uso do paradigma indiciário para fazer uma investigação que construa o raciocínio a partir de indícios existentes na situação. Trata-se de um método usado por vários profissionais para fazer um diagnóstico, sejam eles médicos, historiadores, policiais ou psicanalistas. Esta abordagem é essencialmente clínica, portanto muito diferente dos métodos do engenheiro: este aplica métodos muito estruturados, frequentemente utilizados através de suportes informatizados, que consistem muitas 
vezes em assinalar campos pré-estabelecidos. 0 método clínico que advogo, por outro lado, muitas vezes trabalha a partir de indícios inesperados, como por exemplo os cabelos do paciente podem dar pistas ao médico. Assim como cada paciente é singular, cada empresa, cada caso tem sua singularidade. Ao mesmo tempo, há uma espécie de paradoxo aparente na clínica: nós somos conduzidos por um conhecimento anterior, que é chamado por alguns autores de conhecimento de fundo. Se fizéssemos um pouco de psicanálise dos nossos conhecimentos, há uma espécie de bricolagem das ideias; é difícil especificar com clareza do que se trata, pois é um conjunto de conhecimentos formado por muitas informações, exemplos, conversas com colegas... O que eu entendo deste paradigma dos indícios é simplesmente reconhecer que trabalhamos a partir de indícios, de traços, e que faremos efetivamente todo um trabalho para desenvolver tais indícios, ligá-los entre si e desenvolver uma ideia sobre aquilo que causou o fato que estudamos.

É claro também que o diagnóstico depende muito das características pessoais, da experiência anterior e um pouco da sorte. Talvez o aspecto mais impor- tante deste paradigma dos indícios seja o fato de que se trata de uma investigação na qual o investigador está dentro da investigação: ao mesmo tempo em que é importante se questionar sobre os indícios, é importante também se questionar sobre si e sobre sua própria conduta. Isto me leva à conclusão de que há um campo aberto no qual faltam relatos de diagnósticos realizados e que ao mesmo tempo falem do investigador. Por isso é tão importante que nós nos engajemos em fazer relatos de nossas experiências, que não precisam ser diagnósticos muito completos ou extremamente precisos, mas que revelem explicitamente a pessoa que os fez, que ela se apresente e esclareça que partido tomou naquilo que fez.

\section{Agradecimentos}

O Fórum de Acidentes de Trabalho agradece aos Procuradores do Ministério Público do Trabalho da $15^{\text {a }}$ Região pelo apoio viabilizado por meio de Termo de Ajuste de Conduta que propiciou as condições financeiras para a realização dos encontros presenciais realizados em 2012 que incluíram as Conferências de Michel Llory, sua tradução e edição para esta entrevista. 